Portland State University

PDXScholar

\title{
Optimal Design of Compact and Functionally Contiguous Conservation Management Areas
}

Hayri Önal

University of Illinois at Urbana-Champaign

Yicheng Wang

Qingdao Agricultural University

Sahan T.M. Dissanayake

Portland State University, sahan@pdx.edu

James D. Westervelt

U.S. Army Engineer Research and Development Center-Construction Engineering Research Laboratory

Follow this and additional works at: https://pdxscholar.library.pdx.edu/econ_fac

Part of the Economics Commons

Let us know how access to this document benefits you.

\section{Citation Details}

Önal, H., Wang, Y., Dissanayake, S. T., \& Westervelt, J. D. (2016). Optimal design of compact and functionally contiguous conservation management areas. European Journal of Operational Research, 251(3), 957-968.

This Article is brought to you for free and open access. It has been accepted for inclusion in Economics Faculty Publications and Presentations by an authorized administrator of PDXScholar. Please contact us if we can make this document more accessible: pdxscholar@pdx.edu. 


\title{
Optimal design of compact and functionally contiguous conservation management areas
}

\author{
Hayri Önal ${ }^{\mathrm{a}, *}$, Yicheng Wang ${ }^{\mathrm{b}}$, Sahan T. M. Dissanayake ${ }^{\mathrm{c}}$, James D. Westervelt ${ }^{\mathrm{d}}$ \\ ${ }^{a}$ Department of Agricultural and Consumer Economics, University of Illinois at Urbana-Champaign, 1301 West Gregory Drive, 305 Mumford Hall, Urbana, IL \\ 61801, USA \\ ${ }^{\mathrm{b}}$ College of Resources and Environment, Qingdao Agricultural University, 700 Changcheng Road, Chengyang District, Qingdao 266109, China \\ ${ }^{\mathrm{c}}$ Department of Economics, Colby College, Diamond 347,5247 Mayflower Hill, Waterville, ME 04901, USA \\ ${ }^{\mathrm{d}}$ U.S. Army Engineer Research and Development Center-Construction Engineering Research Laboratory (ERDC-CERL), 2902 Newmark Drive, Champaign, IL 61822, \\ USA
}

\section{A R T I C L E I N F O}

\section{Article history:}

Received 17 May 2013

Accepted 1 December 2015

Available online 15 December 2015

\section{Keywords:}

(D) OR in natural resources

Compactness

Landscape connectivity

Integer programming

\begin{abstract}
A B S T R A C T
Compactness and landscape connectivity are essential properties for effective functioning of conservation reserves. In this article we introduce a linear integer programming model to determine optimal configuration of a conservation reserve with such properties. Connectivity can be defined either as structural (physical) connectivity or functional connectivity; the model developed here addresses both properties. We apply the model to identify the optimal conservation management areas for protection of Gopher Tortoise (GT) in a military installation, Ft. Benning, Georgia, which serves as a safe refuge for this 'at risk' species. The recent expansion in the military mission of the installation increases the pressure on scarce GT habitat areas, which requires moving some of the existent populations in those areas to suitably chosen new conservation management areas within the boundaries of the installation. Using the model, we find the most suitable and spatially coherent management areas outside the heavily used training areas.
\end{abstract}

(c) 2015 Elsevier B.V. All rights reserved.

\section{Introduction}

In many parts of the world conservation reserves are established to protect critical habitat areas from agricultural/urban development and managed to maintain or enhance species survival chances. Due to the scarcity of financial resources, determination of the optimal amount and location of those areas is an important issue. Typically, this is done by dividing the landscape into discrete land units (sites) and selecting an optimal subset of them assuming that each site provides measurable habitat services to the targeted species. This problem is often stated as minimization of the cost of selected sites while meeting the conservation goals (e.g., minimum occurrence of each species in selected sites), or maximization of a conservation objective (e.g. number of species protected) subject to the available resource constraints (Moilanen, Wilson, and Possingham 2009). These problems were addressed initially by using heuristic approaches (e.g., Pressey, Humphries, Margules, Vane-Wright, \& Williams, 1993, 1997). Later, they were formulated as linear mixed-integer programs (MIP) in the framework of the set covering problem (SCP) and maximal cov-

\footnotetext{
* Corresponding author. Tel.: +1 217333 5507; fax: +1 2173335538.

E-mail addresses: h-onal@illinois.edu, hayrional@gmail.com ( $\mathrm{H}$. Önal), qdwangyc@yahoo.com.cn (Y. Wang), sdissan2@gmail.com (S.T.M. Dissanayake), James.D.Westervelt@erdc.dren.mil (J.D. Westervelt).
}

ering problem (MCP) (Camm, Polasky, Solow, \& Csuti, 1996; Church \& ReVelle, 1974; Church et al. 1996; Cocks \& Baird, 1989; Kirkpatrick, 1983; Polasky, Camm, \& Garber-Yonts, 2001; Possingham, Ball, \& Andelman, 2000; Toregas \& ReVelle, 1973; Underhill, 1994; Williams \& ReVelle, 1997). Although the optimal solutions of these MIP formulations are economically efficient, they usually lack spatial coherence. This may limit the chances of inter-site dispersal and long-term survival of species within the conservation reserve areas. Also, managing a spatially coherent reserve network is more convenient and efficient than managing many sites scattered over a large area. Therefore, additional mechanisms need to be introduced in the SCP and MCP formulations to take spatial properties into account when determining the optimal site selection.

Spatial criteria in reserve site selection may take a variety of forms (Haight \& Snyder, 2009; Williams, ReVelle, \& Levin, 2005). Most commonly used criteria include compactness (Fischer \& Church, 2003; Jafari \& Hearne, 2013; Önal and Briers, 2003; Tóth \& McDill 2008; Wright, ReVelle, \& Cohon, 1983), proximity of selected sites (Briers 2002; Dissanayake, Önal, Westervelt, \& Balbach, 2012; Miller, Snyder, Skibbe, \& Haight, 2009; Nalle, Arthur, Montgomery, \& Sessions, 2002; Önal and Briers, 2002; Rothley, 1999; Snyder, Miller, Skibbe, \& Haight, 2007; Williams, 2008), habitat fragmentation (Önal \& Briers, 2005; Önal \& Wang, 2008), contiguity (Cerdeira \& Pinto, 2005; Cerdeira et al., 2005, 2010; Cova \& Church, 2000; Duque 
et al., 2011; Jafari \& Hearne, 2013; Marianov, ReVelle, \& Snyder, 2008; Önal \& Briers, 2006; Tóth et al., 2009; Wang \& Önal, 2011, 2013; Williams, 2001; Carvajal et al., 2013), existence of buffers and corridors (Conrad, Gomes, van Hoeve, Sabharwal, \& Suter, 2012; Williams, 1998; Williams \& ReVelle, 1996, 1998; Williams \& Snyder, 2005), and accessibility (Önal \& Yanprechaset, 2007; Ruliffson, Haight, Gobster, \& Homans, 2003). Incorporating these criteria in optimum site selection requires more sophisticated and computationally complex mathematical models than the SCP and MCP formulations. Consideration of multiple attributes together increases this challenge further. This article presents a linear integer programming model to incorporate compactness and connectivity criteria simultaneously.

Connectivity is an important factor for efficient functioning of conservation reserves. A well-connected reserve network ${ }^{1}$ allows the species to utilize all the resources available in the reserve and increases the likelihood of species survival and ability to colonize suitable habitat areas. This depends not only on the habitat characteristics of an individual reserve site, but also on the characteristics of the neighboring reserve sites (Van Teeffelen et al., 2006). Connectivity is approached in different ways. Metapopulation connectivity deals with spatially separated but interacting local populations in the reserve network (Hanski, 1999; Moilanen \& Hanski, 1998; Moilanen \& Hanski 2001). Landscape connectivity, on the other hand, deals with the degree to which the landscape facilitates movement of species within reserves. Landscape connectivity can be achieved either by structural connectivity (or physical contiguity) that allows species to dwell in the reserve without having to get out of the protected area, or functional connectivity which deals with the degree to which a reserve facilitates species' capability to move within the reserve (Bunn, Urban, \& Keitt, 2000; Taylor, Fahrig, \& With, 2006; Taylor, Fahrig, Henein, \& Merriam, 1993; Tischendorf \& Fahrig, 2000; Urban \& Keitt 2001). A structurally connected reserve may not necessarily be functionally connected if physical characteristics of some sites impede movement within or between the reserved areas (e.g. presence of steep rocky terrains or water bodies, lack of sufficient vegetation or forest cover). Although the importance of functional connectivity has been widely acknowledged, a generally agreed upon operational definition of the concept is not yet available (Bélisle, 2005; Kadoya, 2009). Incorporating these two connectivity criteria in site selection may lead to dramatically different configurations. For instance, minimization of the reserve size along with the physical contiguity requirement may lead to an elongated, narrow and winding reserve configuration containing the best available but spatially dispersed sites (see, for instance, Cerdeira, Gaston, \& Pinto, 2005; Önal \& Briers, 2006; Williams \& Snyder, 2005 ). This would increase the likelihood of species' exposure to unfavorable conditions within and outside the reserve area and may not work effectively if the individuals tend to roam around or move in random directions. A contiguous reserve configuration may include poor quality sites just to obtain physical connections (bridges) between good habitats. Such a reserve would not be functionally connected if the targeted species do not have the capability to cross those bridging sites. Therefore, in essence the reserve would consist of multiple 'functionally detached' sub-reserves some of which may not be large enough to provide adequate habitat services for a minimum viable population of the target species. On the other hand, a functionally connected reserve may not be structurally connected if the species (e.g. birds, butterflies) can crossover between closest, but not necessarily adjacent areas in the reserve. In many cases a network of multiple connected reserves is a preferred configuration than a single large connected reserve to safeguard against catastrophic events

\footnotetext{
1 Throughout the paper we use the term 'reserve' for a collection of sites that work together to serve a viable population of one or more targeted species. A 'reserve network' consists of multiple reserves that collectively serve a sufficiently large total population of each targeted species.
}

such as fire, diseases, etc. ${ }^{2}$ In this article we address these issues and present a linear integer programming model to determine an optimal compact and connected reserve network configuration where connectivity can be enforced in the form of structural connectivity and/or functional connectivity. We apply this approach to the protection of a ground-bound species where compactness, structural connectivity, and functional connectivity must be enforced together.

\section{Problem description}

Many rare, threatened, and endangered species in the U.S. are found within the boundaries or in the vicinity of military installations (Flather, Joyce, \& Bloomgarden, 1994; Flather, Knowles, \& Kendall, 1998; Stein, Scott, \& Benton, 2008). ${ }^{3}$ The Department of Defense (DoD) allocates a significant amount of capital, human resources and land for conservation efforts toward protecting and managing wildlife habitat in and around military installations. ${ }^{4}$ Ft. Benning, Georgia, is one of those installations where several endangered, threatened, and at-risk species are under protection. In this article we consider a particular keystone species, Gopher Tortoise (Gopherus polyphemus), which has an 'at risk' status and currently has an extensive population in Ft. Benning. The installation is currently undergoing an expansion of its military mission that requires converting more lands into military training areas. Therefore, managing those lands in the best possible way as an alternative to costly arrangements, such as purchasing additional land or acquisition of property rights for lands around the installation, is an important issue. The land managers plan to identify lands outside of the current and future military training areas for maintaining sustainable GT populations (including the relocated populations and populations that might be brought from outside the installation). These areas, called 'Conservation Management Areas' (CMA), will be used less for military training purposes or assigned to appropriate training exercises to the extent possible. Since GT is a ground-bound species, a selected CMA should be as compact as possible and connected both structurally and functionally in order to facilitate movement of GTs in those areas. In addition, if multiple CMAs are to be configured, each CMA must be large enough to sustain a minimum viable GT population in it. We note that interaction of the protected GT populations in different CMAs is not an issue, which means that two CMAs can be located at distant parts of the installation. Thus, connectivity (both structural and functional) is required at local (landscape) level, not at the entire CMA network level.

\section{The model}

To address the issues described above we first partition the area considered for development of a conservation reserve ${ }^{5}$ into disjoint spatial units (e.g., a uniform square grid $\operatorname{cover}^{6}$ ). Each spatial unit (site) is either selected and becomes part of a reserve in the network or is left out. When selecting sites the spatial locations of indi-

\footnotetext{
2 For the merits of establishing multiple reserves see Zhou and Wang (2006).

${ }^{3}$ Although the total amount of land controlled by the DoD is only 3.4 percent of the federally administered lands, 26 percent of the threatened and endangered species occurs on the military lands (Flather et al., 1994).

${ }^{4}$ In 2006, for instance, the DoD spent $\$ 4.1$ billion on environment related expenses of which \$1.4 billion was for environment restoration and \$204.1 million was for conservation (Benton et al., 2008). The DoD also implements various management policies on military lands including protection of endangered, threatened and at-risk species (Diersing et al., 1992; DoD (2011, p.12).

${ }^{5}$ Here we use the term 'reserve' to refer to the protected areas in general. In the empirical application we use the term CMA instead of 'reserve' because the military does not really view these areas as 'reserves'; the conservation objectives are always secondary and subject to the military objectives.

${ }^{6}$ The cover may consist of triangles, rectangles, polygons, or irregular shapes. Thus, the square grid assumption is not restrictive. Throughout the paper we will use the terms 'cell' and 'site' interchangeably.
} 
vidual sites relative to other selected sites and their contributions to the conservation objectives are both taken into account. For reasons that will be explained later, we represent each reserve by a 'central site' to which other selected sites are assigned. Both the central site and assignment of sites to the center are determined by the model simultaneously.

The algebraic notation used in the model is as follows: $n \geq 1$ denotes the number of reserves in the network. $L$ is the set of all sites where individual sites are denoted by symbols $i, j, k \in L$. Site selection and assignment to a reserve is represented by a binary variable $X_{k i}$, where $X_{k i}=1$ if site $i$ is selected and belongs to the reserve centered at site $k$ and $X_{k i}=0$ otherwise. If $X_{k k}=1$, then site $k$ is selected as a central site to form a reserve around it. The symbol $d_{k i}$ denotes the distance between the centroids of sites $k$ and $i$, and $h_{i}$ denotes the habitat quality of site $i$. Each reserve is required to provide a minimum amount of habitat quality, denoted by $v h$, in order to support a viable population of the targeted species. Finally, the total habitat quality provided by all reserves must exceed a specified level denoted by th.

\subsection{Modeling compactness}

Compactness is considered as a measure of shape simplicity and equated to near circular or square shapes. Although the concept may seem obvious, there is no universally agreed upon definition of compactness in the spatial analysis literature (see Young, 1988, for various definitions and why none is fully satisfactory). In the present analysis we use the total distance between all sites that form a reserve and the central site of the reserve as a measure of compactness. If the total distance associated with a reserve is smaller than that of another reserve of the same size, the former is considered as more compact. Thus, to configure a compact reserve, the model selects an optimal central site and assigns sites to the center in such a way that the total distance between the assigned sites and the central site is minimized. This approach promotes circular reserve configurations. If a reserve network including multiple compact reserves is to be configured the compactness measures of individual reserves are summed across all reserves and the sum is optimized. This is an instance of the p-median problem (Christofides, 1975). An algebraic representation of the model is given below.

$$
\begin{aligned}
& \text { Minimize } \sum_{k} \sum_{i} d_{k i} \cdot X_{k i} \\
& \text { s.t. } \quad \sum_{k} X_{k k}=n \\
& \sum_{k} X_{k i} \leq 1 \quad \text { for all } i \\
& \sum_{i} X_{k i} \leq m \cdot X_{k k} \quad \text { for all } k, \\
& \sum_{i} h_{i} \cdot X_{k i} \geq v h \cdot X_{k k} \quad \text { for all } k \\
& \sum_{k} \sum_{i} h_{i} \cdot X_{k i} \geq t h \\
& X_{k i}=0,1
\end{aligned}
$$

The objective function (1) is the sum of distances from individual sites in each reserve to the center of that reserve, summed over all reserves. Eq. (2) ensures that $n$ reserves are configured. ${ }^{7}$ Constraint

\footnotetext{
${ }^{7}$ In (2), the number of reserves is specified exogenously. Alternatively, we may state constraint (2) as a type inequality, specify $n$ as a reasonably large integer, and let the model choose the optimal number of reserves (which will be given by $\sum_{k} X_{k k}$ ).
}

(3) states that each site can belong to at most one reserve. Constraint (4) implies that if site $k$ is selected as a central site, i.e., $X_{k k}=1$, then up to $m$ sites can be assigned to the reserve formed around site $k$, where $m$ is an arbitrarily selected large integer. Otherwise, $X_{k k}=0$ and no site can be assigned to it, i.e. $X_{k i}=0$ for all $i$. Conversely, if site $i$ is selected and assigned to a central site $k$, i.e. $X_{k i}=1$, then a reserve must be formed around (centered at) site $k$, i.e. $X_{k k}=1 .^{8}$ Constraint (5) requires that each reserve provides the minimum habitat quality required from individual reserves, while constraint (6) ensures that all reserves collectively provide the desired aggregate level of habitat quality.

\subsection{Modeling connectivity}

In the landscape ecology literature a distinction has been made between structural connectivity and functional connectivity (Bunn et al., 2000; Tischendorf \& Fahrig, 2000). Structural connectivity refers to the spatial arrangement of sites in a reserve and can be achieved if the closest sites in the reserve are within a specified threshold crossable distance $\bar{d} \geq 0$ from each other. This property is often stated as physical contiguity where the closest sites are adjacent $(\bar{d}=0)$. In this case any two spatial units in the protected area are connected through a path of mutually adjacent spatial units. Functional connectivity reflects the degree to which the connecting sites that make up those paths are 'traversable' by the targeted species. Therefore, reserving an inhospitable site between two goodquality sites may satisfy the spatial contiguity requirement, but if that site cannot be crossed easily by the targeted species, the path would not actually serve as a functional connection. On the other hand, a chain of disconnected sites in a reserve may allow the movement of targeted species through those sites where the nearest sites can be used as stepping stones for crossing inhospitable areas (Williams \& Snyder, 2005). Such a reserve would be functionally connected although it is not structurally connected (contiguous). Therefore, the two forms of connectivity may not always imply each other and may lead to dramatically different reserve configurations. Here, we consider both physical contiguity and functional connectivity as desirable reserve attributes.

In general, the model described by (1)-(7) results in spatially contiguous reserve selections, but this is not always guaranteed. The optimal solution may exhibit a fragmented reserve if a set of highquality sites detached from all other selected sites makes sufficient contribution to the habitat quality at a lower cost or the total distance of those sites from the center is less than the summed distances of multiple alternative sites all attached to the rest of the reserve. Therefore, an additional explicit mechanism needs to be introduced to ensure spatial contiguity. This is done by adding the following constraint to the model:

$X_{k j} \leq \sum_{\substack{i \in N_{j}, d_{k i}<d_{k j}}} X_{k i}$ for all $k, j$ that are not adjacent

where $N_{j}$ denotes the set of immediate neighbors of site $j$. Constraint (8) implies that if a reserve is configured around site $k$ and site $j$ belongs to that reserve, thus $X_{k j}=1$, at least one of the neighbors of site $j$ that is closer to site $k$ must be selected and belong to the same reserve, i.e. $X_{k i}=1$ for some $i$. By applying the same argument to the latter site and repeating this procedure iteratively until reaching site $k$, one can generate a chain of mutually adjacent sites, i.e. a path, all contained in that reserve (see Fig. 1 for a graphical illustration). Thus, every selected site is spatially connected to the central site $k$. Furthermore, for any pair of sites $j$ and $i$ in the same reserve there is a path

\footnotetext{
${ }^{8}$ An equivalent formulation of constraint (4) is $X_{k i} \leq X_{k k}$ for all $i, k$. Although this formulation implies a substantially larger number of constraints, our computational experience shows that it performs better than the one given in (4). We cannot generalize this, however, due to the limited computational evidence.
} 


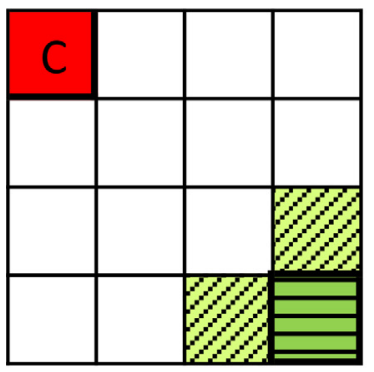

(1a)

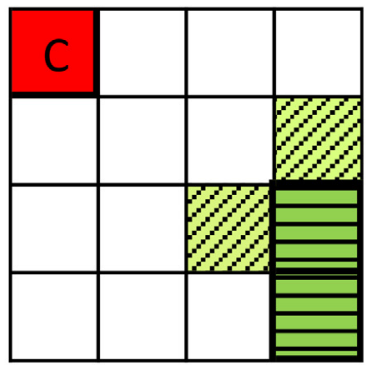

(1b)

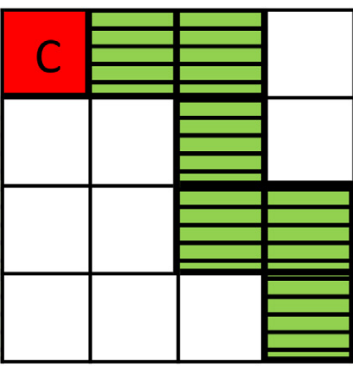

(1c)

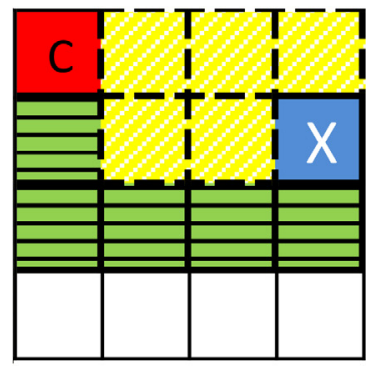

(1d)

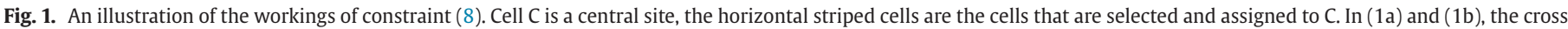

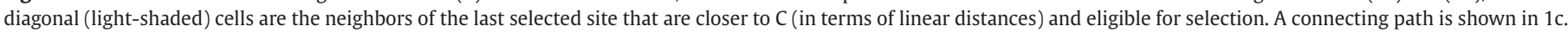

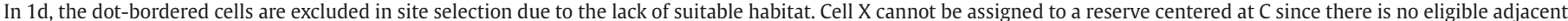
cell that is closer to C. Defining the distance as the length of the shortest eligible path allows assigning X to C through the horizontal striped cells.

that connects the two sites, namely the union of the paths connecting those sites to the common center. Therefore, constraint (8) ensures that each reserve is spatially connected. ${ }^{9}$

The strategy employed in the contiguity constraint (8) was introduced earlier by Zoltners and Sinha (1983) in the context of a sales territory alignment problem with known distribution centers (roots) and later by Cova and Church (2000) when determining a contiguous region around a given central unit. This problem is termed as the rooted regionalization problem. Duque, Church, and Middleton (2011) present alternative linear integer programming formulations to configure a specified number of spatially contiguous regions around given centers while minimizing heterogeneity within each region. They formulate the objective function as minimization of the sum of spatial dissimilarity. If the dissimilarity is measured in terms of distances to the roots, as in (1), their models promote clustering (compactness) as well. The model presented by Cova and Church (2000) includes additional variables and constraints to minimize the reserve boundary. A smaller boundary size is an indicator of higher compactness. The problem we address here is the unrooted version of the problem described above where the centers are not available beforehand. Rather, they are determined by the model together with the assignment of sites to the selected centers. This problem was addressed by employing graph theoretic concepts in mixed integer programming (Cerdeira et al. 2005; Shirabe, 2005; Williams, 2001; and Önal \& Briers, 2006). In this approach a graph is overlaid on the region where each site corresponds to a node and a directed arc is defined for each pair of adjacent nodes (sites). The selected sites correspond to a sub-graph where one of the nodes serves as a sink to which each node is connected through a set of mutually adjacent nodes and arcs between them (thus forming a tree). The problem is then stated as determining a minimal tree that satisfies specified regionalization targets. Contiguity is ensured by eliminating the possibility of cycle (or sub-tour) formation in the sub-graph when selecting nodes and arcs. The sub-tour elimination problem is not a straight forward matter, however, because a large number of cycle-breaking constraints is needed even in problems with moderately large number of nodes (Miller, Tucker, \& Zemlin, 1960). Shirabe (2005) and Önal and Briers (2006) introduced flow-based graph theoretic models, formulated as MIPs, for the contiguous regionalization and conservation reserve design problems. None of these studies incorporated compactness as an explicit criterion, however. Duque et al. (2011) presented a similar graph theoretic formulation coupled with the p-region formulation

\footnotetext{
${ }^{9}$ Constraint (8) can be modified to allow tolerable discontinuities by defining $N_{j}=$ $\left\{i: d_{i j} \leq \bar{d}\right\}$, where $\bar{d}>0$ denotes the maximum crossable distance. The solution may now include sites that serve as stepping stones instead of fully contiguous paths. Also, functional distances can be used instead of ordinary distances when defining the neighborhood $N_{j}$ in (8).
}

where the dissimilarity of the areas within each region is minimized. If dissimilarity is measured by pairwise distances, the model solves the unrooted and compact regionalization problem. More recently, Jafari and Hearne (2013) presented a graph theoretic transshipment model where the flow of capital through the network is optimized. In the model budget flows from an initial source node to one of the nodes or between adjacent nodes, where the demand at a node is met when the corresponding site is selected and the purchase cost is paid (thus determining the capital outflow). The model considers flows only between adjacent nodes and the outflows decrease monotonically, therefore reserve contiguity is ensured automatically. Jafari and Hearne also introduce a variant of their model to promote compactness of the reserve by minimizing the perimeter of the selected sites excluding the shared boundaries. For this, additional constraints are introduced and the objective function is stated as a weighted sum of the utility from conservation and perimeter of the selected area.

The graph-theoretic formulations employing cycle-breaking constraints lead to large and computationally difficult MIP models. The computational disadvantage is exacerbated and can be fatal particularly when multiple reserves are to be configured from a large number of sites. ${ }^{10}$ In the next section we test and compare the computational efficiency of the model described by (1)-(8) vis-à-vis the above graph theoretic models using various randomly generated data sets.

In the model (1)-(8) Euclidean or other simple distance measures may work well in most practical applications. However, there may be instances where constraint (8) is not satisfied and an otherwise favorable site may not be part of a feasible solution. An illustrative example is given in Fig. 1d where the horizontal striped sites are allowed for selection while the diagonal striped sites are ineligible due to lack of habitat. Suppose the distance between a pair of sites is defined as the sum of center-to-center distances traveled through the minimum number of sites that connect those sites disregarding the eligibility of the intermediate sites. Constraint (8) would not allow selection of the site labeled with $\mathrm{X}$ because it has no immediate neighbor that is closer to the central site labeled with C. To overcome this anomaly we define the distance between any two sites as the length of the shortest path formed by 'eligible sites only'. According to this definition the distance between $X$ and $C$ is 6 (the minimal path is comprised by the horizontal striped sites). Since the distance between $C$ and the site just below $\mathrm{X}$ is 5 , constraint ( 8 ) becomes feasible and selection of $\mathrm{X}$ is now allowed.

When functional connectivity is of concern, the degree to which a connecting path facilitates or impedes movement of species would depend not only on the distance but also on the habitat quality of the individual sites in that path. This is not taken into account

\footnotetext{
${ }^{10}$ For example, Duque et al. (2011) report that problems containing up to 49 units and 10 regions could not be solved to optimality within three hours of processing time.
} 
in constraint (8). Therefore, an optimal solution may include some sites with poor habitat quality just because their selection provides bridges to physically connect high-quality habitat patches. Instead, a longer path formed by sites with moderately good habitat may be a preferred alternative if this offers a more convenient movement across the protected areas. This leads to the concept of functional distance (or habitat-adjusted distance), $\tilde{d}_{i j}$, defined by:

$\tilde{d}_{i j}=\left\{\begin{array}{l}d_{i j} /\left[0.5\left(h_{i}+h_{j}\right)\right], \text { if } h_{i}, h_{j}>l \\ m \text { otherwise }\end{array}\right\}$

where $i$ and $j$ are adjacent sites (have a common edge), $l$ is a threshold habitat level required by the species to dwell in or cross those sites, and $m>0$ is an arbitrarily selected large number. All other symbols are as defined earlier. The functional distance between any two sites (not necessarily adjacent) is then defined as the length of the shortest path with respect to functional distances between mutually adjacent sites in that path. When both $h_{i}$ and $h_{j}$ are larger than the threshold habitat level $l$, the denominator term represents the average habitat level of sites $i$ and $j$. Therefore, the value of $\tilde{d}_{i j}$ is small (large) if both sites have good (poor) habitat. If one of the two sites has less than the threshold habitat level, then $\tilde{d}_{i j}$ becomes very large (namely equal to $m$ ). This would drive out such pairs of sites when identifying the best functional connections (routes), which is consistent with the movement behavior of species that do not generally venture into poor quality areas. ${ }^{11}$

The functional distance and shortest path approach described above is similar to the least-cost path method used in spatial analysis where the purpose is to find a path which links a given origin and destination and minimizes the transportation cost between them. If we interpret the inverse of the average habitat quality used in (9) as the 'travel cost' of moving from site $i$ to site $j$, the model incorporating $\tilde{d}_{i j}$ in the objective function determines the least-cost network including multiple origins and destinations and the least-cost paths between them to minimize the total cost associated with the entire network. In the ecological context, $\tilde{d}_{i j}$ can be considered as a measure of movement resistance, thus minimizing the objective function (1) expressed in this distance measure determines the optimal habitat areas to facilitate movement of species within those areas to the extent possible. ${ }^{12}$ The concept of movement resistance measured by the total travel cost has been discussed extensively in the ecology literature (Adriaensen et al., 2003; Pinto \& Keitt, 2009; see Zeller, McGarigal, \& Whiteley, 2012, for a review). The least-cost path length is considered as a good operational measure of functional connectivity (Bélisle, 2005).

To explain the concept of habitat-adjusted distances and functional connectivity, consider the example given in Fig. 2 which shows a section of a potential conservation area from which a reserve is to be configured. Suppose cell $3 c$ is a highly favorable site, and cell $1 \mathrm{a}$ is the central site of the reserve. There are several paths connecting $3 c$ to $1 \mathrm{a}$, namely $\mathrm{P} 1=\{1 \mathrm{a}, 1 \mathrm{~b}, 1 \mathrm{c}, 2 \mathrm{c}, 3 \mathrm{c}\}, \mathrm{P} 2=\{1 \mathrm{a}, 1 \mathrm{~b}, 2 \mathrm{~b}, 2 \mathrm{c}, 3 \mathrm{c}\}$, $\mathrm{P} 3=\{1 \mathrm{a}, 1 \mathrm{~b}, 2 \mathrm{~b}, 3 \mathrm{~b}, 3 \mathrm{c}\}, \mathrm{P} 4=\{1 \mathrm{a}, 2 \mathrm{a}, 2 \mathrm{~b}, 2 \mathrm{c}, 3 \mathrm{c}\}, \mathrm{P} 5=\{1 \mathrm{a}, 2 \mathrm{a}, 2 \mathrm{~b}, 3 \mathrm{~b}, 3 \mathrm{c}\}$, and $\mathrm{P} 6=\{1 \mathrm{a}, 2 \mathrm{a}, 3 \mathrm{a}, 3 \mathrm{~b}, 3 \mathrm{c}\}$. Suppose the distance between all adjacent sites is 1.0. Therefore, all six paths have the same length, namely 4 . The total habitat qualities associated with the six paths (sum of the habitat qualities of the selected sites, denoted by TH in the figure) are 10.0,

\footnotetext{
11 Alternatively, the below-threshold habitat sites can be excluded during model generation. However, in some cases the large- $m$ formulation may be useful. It allows including some non-traversable sites in the optimal solution if their inclusion connects high quality habitat patches. This may provide valuable information to conservation managers in terms of habitat restoration.

12 Using Euclidean distances in the objective function promotes circular reserve shapes, but this may leave out some functionally well-connected sites. On the other hand, using functional distances promotes the selection of well-connected sites, but this may compromise compactness and lead to skewed/stretched shapes instead of circular configurations. Etherington and Holland (2013) argue that least-cost paths explain species movement patterns better and should be preferred to shortest paths.
}

9.1, 8.2, 11.6, 10.7, and 11.1, respectively. Therefore, if we consider plain distances only, path $\mathrm{P} 4$ is the most preferred spatially connected selection since it has the highest total habitat quality (followed by P6 which has the second highest $\mathrm{TH}$ ). However, when functional distances are of concern, the optimal selection becomes quite different. Using (9), the habitat-adjusted lengths of P1-P6 are calculated as 2.74, $4.00,12.26,3.00,11.26$ and 4.55 , respectively (denoted by HAD in the figure). In this case, P1 would be the preferred selection because of the improved functional connectivity. The second best path, P6, provides more habitat quality than $\mathrm{P} 1$, but its functional connectivity is worse compared to that of P1 (4.55 versus 2.74). This is because of the inclusion of poor sites in P4 and P6 (cells $2 \mathrm{~b}$ and $3 \mathrm{~b}$, respectively). Note that the order of sites in a given path affects the functional connectivity although the total habitat value remains the same. For instance, presence of two side by side poor habitats may reduce functional connectivity substantially, as in the case of P3 and P5. The latter path is particularly noteworthy. Although its total habitat value is significantly higher than that of $\mathrm{P} 1$, the functional connectivity of P5 is four times less because of the presence of two poor adjacent sites (namely cells $2 \mathrm{~b}$ and $3 \mathrm{~b}$ ).

When working with functional distances, constraint (8) can be used in a similar way to using ordinary distances, i.e. if a site is to be selected a neighboring site that has a shorter functional distance to the central site must also be selected. However, unlike the ordinary distances, functional distances may restrict the eligibility of neighbors in site selection. Fig. 2 displays an example. Since the functional distance between $3 \mathrm{c}$ and $1 \mathrm{a}$ is 2.74 , one of the neighbors of $3 \mathrm{c}$ that has a smaller functional distance to $1 \mathrm{a}$ must also be selected. The functional distance between $2 \mathrm{c}$ and $1 \mathrm{a}$ is 2.37 (minimum of the lengths of paths $\{1 a, 1 b, 1 c, 2 c\},\{1 a, 1 b, 2 b, 2 c\}$ and $\{1 a, 2 a, 2 b, 2 c\})$, therefore $2 c$ meets this requirement and can be included in a connecting path. The other neighbor $3 \mathrm{~b}$ is ineligible, however, because its functional distance to $1 \mathrm{a}$ is 4.11 (minimum of the lengths of paths $\{1 \mathrm{a}, 1 \mathrm{~b}, 2 \mathrm{~b}, 3 \mathrm{~b}\}$, $\{1 \mathrm{a}, 2 \mathrm{a}, 2 \mathrm{~b}, 3 \mathrm{~b}\}$ and $\{1 \mathrm{a}, 2 \mathrm{a}, 3 \mathrm{a}, 3 \mathrm{~b}\})$, which is greater than the functional distance of $3 c$. This rules out the possibility of connecting $3 c$ to $1 \mathrm{a}$ through $3 b$. Once $2 c$ is selected, both of its neighbors (1c and $2 b$ ) are eligible for selection because their functional distances to $1 \mathrm{a}$ ( 1.37 and 0.82 , respectively) are less than the distance of $2 c$. Selecting $2 b$ adds a larger habitat adjusted distance than selecting $1 \mathrm{c}$, however, because of the larger habitat adjusted distance between $2 \mathrm{~b}$ and $2 \mathrm{c}$. Once $1 \mathrm{c}$ is selected, $1 \mathrm{~b}$ is the only choice, completing the shortest path P1. Note that the selection of $\mathrm{P} 1$ does not preclude the selection of $2 \mathrm{a}$, which is a habitat rich site. If more habitat is needed after selecting the entire path P1, 2a may be selected and connected to 1a to acquire more quality habitat. This generates another connecting path from a selected site to the central site.

We note two important characteristics of the optimal solutions obtained from the model with the use of habitat adjusted distances. First, the optimal reserve configuration is always structurally contiguous. This is because constraint (8) enforces the selection of an immediately adjacent neighbor when selecting a reserve site. Second, selection of a particular site does not necessarily require selection of the entire shortest path connecting that site to the associated central site. Although this would happen in most cases, there is no explicit mechanism in the model that enforces this property.

To investigate the merits of the approaches described above in terms of compactness and functional contiguity of the resulting reserve configuration, we generated several synthetic data sets and solved the model. Fig. 3 displays the results of one of those runs where two compact and connected reserves are generated. The optimal configuration considering linear distances is depicted in Fig. 3a while Fig. 3b shows the solution considering the habitat-adjusted distances. Although both reserves in Fig. 3a are structurally connected, neither of them is functionally connected since they have two and one gap sites, respectively (the diagonal-striped cells). These gap sites are needed to 'pack' a few habitat-rich isolated sites (such as the 

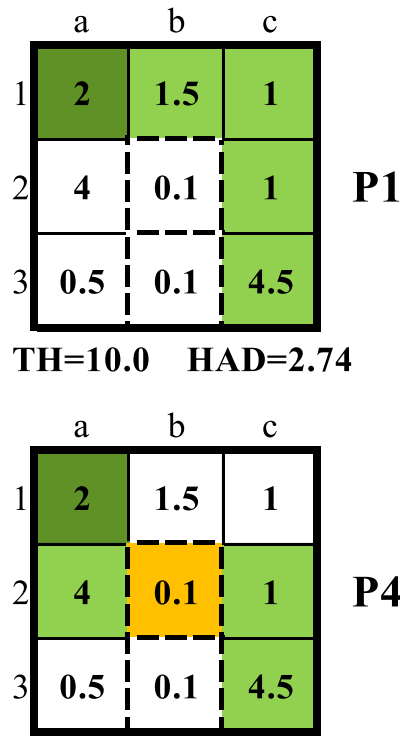

TH=11.6 HAD $=3.00$
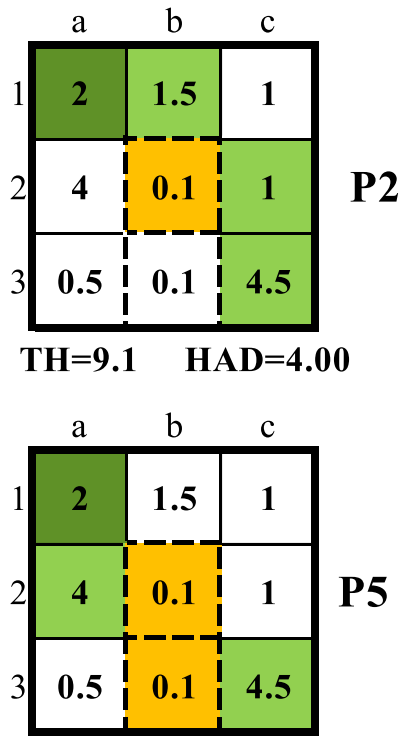

$\mathbf{T H}=10.7 \quad \mathrm{HAD}=\mathbf{1 1 . 2 6}$

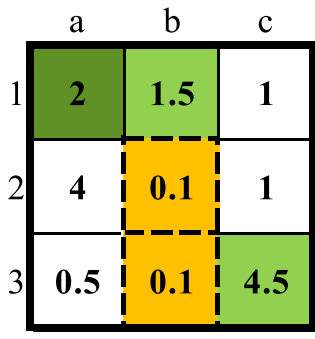

P3

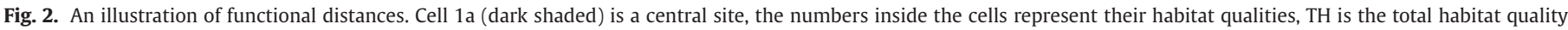

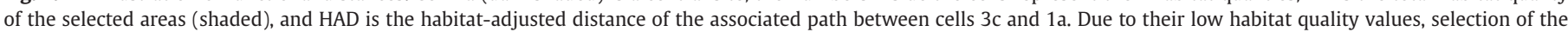
dot-bordered cells ( $2 \mathrm{~b}$ and $\mathrm{3b}$ ) reduces functional connectivity of $1 \mathrm{a}$ and $3 \mathrm{c}$.

\begin{tabular}{|c|c|c|c|c|c|c|c|c|c|}
\hline 2.1 & 3 & 1.1 & 1 & 1 & 4 & 4.1 & 0 & 1.1 & 0.5 \\
\hline 1.1 & 0.1 & 2.2 & 0.5 & 2.5 & 4 & 4.1 & 0 & 7.5 & 1 \\
\hline 0 & 0.2 & 2.5 & 1.1 & 1.5 & 3.8 & 0 & 0 & 6 & 2.5 \\
\hline 1 & 3.5 & 2.6 & 1.4 & 1.5 & 1 & 0 & 0 & 6 & 1 \\
\hline 1.5 & 3.3 & 3.1 & 0 & 3.3 & 4.2 & 0 & 0 & 0 & 2 \\
\hline 2.1 & 3.8 & 0 & 0 & 0 & 0 & 0 & 3.5 & 1.5 & 1 \\
\hline 2.1 & 4.1 & 4 & 0 & 4.5 & 0 & 4 & 4 & 2 & 1 \\
\hline 2 & 0 & 0 & 0 & 0 & 5.1 & 3 & 3 & 2 & 2 \\
\hline 3 & 3 & 4 & 0 & 1.3 & 4 & 3.1 & 3 & 3 & 2 \\
\hline 2.1 & 4.1 & 4 & 0 & 1 & 1.6 & 2.5 & 3 & 2.5 & 2.1 \\
\hline
\end{tabular}

(3a)

\begin{tabular}{|c|c|c|c|c|c|c|c|c|c|}
\hline 2.1 & 3 & 1.1 & 1 & 1 & 4 & 4.1 & 0 & 1.1 & 0.5 \\
\hline 1.1 & 0.1 & 2.2 & 0.5 & 2.5 & 4 & 4.1 & 0 & 7.5 & 1 \\
\hline 0 & 0.2 & 2.5 & 1.1 & 1.5 & 3.8 & 0 & 0 & 6 & 2.5 \\
\hline 1 & 3.5 & 2.6 & 1.4 & 1.5 & 1 & 0 & 0 & 6 & 1 \\
\hline 1.5 & 3.3 & 3.1 & 0 & 3.3 & 4.2 & 0 & 0 & 0 & 2 \\
\hline 2.1 & 3.8 & 0 & 0 & 0 & 0 & 0 & 3.5 & 1.5 & 1 \\
\hline 2.1 & 4.1 & 4 & 0 & 4.5 & 0 & 4 & 4 & 2 & 1 \\
\hline 2 & 0 & 0 & 0 & 0 & 5.1 & 3 & 3 & 2 & 2 \\
\hline 3 & 3 & 4 & 0 & 1.3 & 4 & 3.1 & 3 & 3 & 2 \\
\hline 2.1 & 4.1 & 4 & 0 & 1 & 1.6 & 2.5 & 3 & 2.5 & 2.1 \\
\hline
\end{tabular}

$(3 b)$

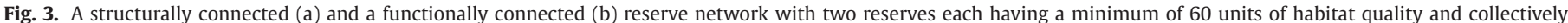

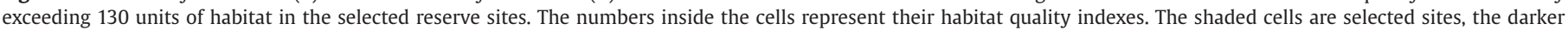

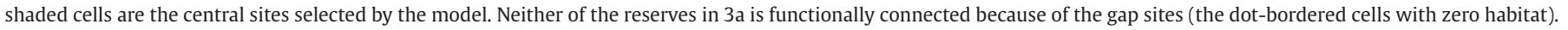

rightmost sites with habitats 7.5, 6, and 6 in the upper reserve and the leftmost site with 4.5 units of habitat in the lower reserve) and connect them to the remaining sites in each reserve. Fig. 3b displays two reserve configurations obtained with the same data but using the habitat adjusted distances instead of ordinary distances. In this case, the two reserves are both structurally and functionally connected. Note that this occurs at the expense of increased reserve size (24 sites versus 22 sites)

\section{Computational efficiency}

In general, discrete optimization models are difficult to solve, even in the linear MIP case, when a large number of constraints and discrete variables is involved. Therefore, the usefulness of the MIP formulation presented above may be an issue in large-scale reserve selection models. In this section, we test the computational efficiency of our formulation against two alternative contiguity and compactness formulations presented by Duque et al. (2011) and Jafari and Hearne (2013). In the comparisons, we use only the third formulation of Duque et al. because they report that it is their most efficient model. ${ }^{13}$ The test problems involved grid partitions containing 251600 cells (sites). To eliminate possible bias due to the input data, the three models were solved using 50 randomly generated data sets,

\footnotetext{
13 That formulation could solve 50 percent of the test problems under two hours of processing time, while the other two models solved only 30 percent and 40 percent. The Jafari-Hearne model does not incorporate site quality, therefore we considered only spatial contiguity when testing our model against Jafari-Hearne.
} 
Table 1

A comparison of the model sizes for alternative formulations before and after GAMS/GUROBI Presolve.

\begin{tabular}{|c|c|c|c|c|c|c|c|}
\hline Number of sites & \multicolumn{2}{|l|}{ Present model } & \multicolumn{4}{|c|}{ Duque et al. model-3c } & Jafari-Hearne model $^{\mathrm{d}}$ \\
\hline \multirow[t]{2}{*}{25} & 1173 & 1138 & 539 & 1051 & 1563 & 2075 & 529 \\
\hline & 626 & 608 & 431 & 561 & 691 & 821 & 317 \\
\hline \multirow[t]{2}{*}{100} & 19,643 & 6966 & 5974 & 11,846 & 17,718 & 23,590 & 2304 \\
\hline & 10,001 & 3654 & 5511 & 6071 & 6631 & 7191 & 1382 \\
\hline \multirow[t]{2}{*}{900} & $1,616,523$ & 285,709 & 414,214 & 827,526 & $1,240,838$ & $1,654,150$ & 21,904 \\
\hline & 810,001 & 144,466 & 409,831 & 415,111 & 420,391 & 425,671 & 13,142 \\
\hline \multirow[t]{2}{*}{1600} & $5,113,763$ & 256,934 & $1,296,484$ & $2,591,366$ & $3,886,248$ & $5,181,130$ & 39,204 \\
\hline & $2,560,001$ & 131,526 & $1,288,641$ & $1,298,081$ & $1,307,521$ & $1,316,961$ & 23,522 \\
\hline
\end{tabular}

a The model size is given for the single reserve case considering the less compact form of Eq (4), $X_{k i} \leq X_{k k}$ for all $i, k$. The number in the first row in each block is the number of equations, the number in the second row is the number of variables. The model size is invariant when multiple reserves are considered.

b The presolved model sizes for multiple reserve cases are slightly different, but differences are negligible.

c $k=$ number of reserves configured. The presolved model sizes are slightly different, but differences are negligible.

d The model size is reported for the single reserve case; the size is invariant when multiple reserves are considered. The presolved model sizes are slightly different, but the differences are negligible.

Table 2

A comparison of the computational efficiency of alternative model formulations.

\begin{tabular}{|c|c|c|c|c|c|c|c|c|c|c|}
\hline \multirow[t]{2}{*}{ Grid size } & \multirow[t]{2}{*}{ Number of cells } & \multicolumn{3}{|c|}{$\begin{array}{l}\text { Present model } \\
\text { Number of reserves }\end{array}$} & \multicolumn{3}{|c|}{$\begin{array}{l}\text { Duque et al. model-3 } \\
\text { Number of reserves }\end{array}$} & \multicolumn{3}{|c|}{$\begin{array}{l}\text { Jafari-Hearne model } \\
\text { Number of reserves }\end{array}$} \\
\hline & & 1 & 2 & 3 & 1 & 2 & 3 & 1 & 2 & 3 \\
\hline $5 * 5$ & 25 & 0.3 & 0.2 & 0.2 & 1.2 & 5.5 & 16.7 & 0.8 & 0.6 & 0.5 \\
\hline $10 * 10$ & 100 & 1.6 & 0.9 & 1.1 & $\mathrm{a}$ & $\mathrm{a}$ & b & 20.9 & 20.3 & 19.0 \\
\hline $20 * 20$ & 400 & 49.0 & 29.0 & 27.3 & a & a & a & $1149.0^{c}$ & $945.3^{c}$ & 967.4 \\
\hline $30 * 30$ & 900 & 110.9 & 116.3 & 114.5 & d & d & d & e & e & e \\
\hline $40 * 40$ & 1600 & $201.4^{\mathrm{f}}$ & $156.3^{f}$ & $140.9^{f}$ & d & d & d & e & e & e \\
\hline
\end{tabular}

a Only two runs could be completed within the allowed processing time limit, relative gaps were $>38$ percent.

b Only one run could find the optimal solution, two other runs were terminated due to the processing time limit, relative gaps were $>83$ percent.

c At most eight runs could be completed within the allowed time limit, the solution times are averages of the completed runs.

d Out of memory while solving the model or terminated due to the processing time limit without finding a solution.

e Only two runs could be completed within the allowed processing time limit, relative gaps were $>36$ percent.

$\mathrm{f}$ Thirty-six or more runs were completed within the allowed processing time limit, the solution times are averages of the completed runs.

each having a different species distribution across the sites and obtained with the same specifications of parameters $n, v h$ and th. The processing time limit for each run was specified as one hour and the solver was terminated after completing 50 runs or after running for two hours (whichever occurs first). We use the problems that are solved successfully by each model and report the average solution times of the completed runs as indicators of the models' computational performance. The test runs were carried out using GUROBI 5.0 on an Intel Pentium computer with a CPU of 2.80 gigahertz and 8 gigabyte RAM.

The model statistics are displayed in Table 1. The number of equations in the Duque et al. model increases almost proportionally with the number of reserves to be configured (due to the inclusion of the reserve index in the variable and constraint definitions). In contrast, the size of the model (1)-(8) remains the same regardless of the number of reserves in the network. Although our model is larger than the Duque et al. model for the cases including less than three reserves, the situation is reversed when four or more reserves are to be configured. A more important point is the size of the actual MIP model solved by GUROBI after performing a preliminary heuristic procedure, Presolve, which eliminates redundant rows and columns. Our model benefits substantially from Presolve whereas the Duque et al. model is almost unaffected. As seen in the table, the reduced size of our model is always smaller than the size of the Duque et al. model in terms of both rows and columns if more than one reserve is to be configured (except one case, with 25 sites and $k=2$ ).
Table 2 reports the computational performance of the three models. The first observation is that the model presented here could solve many more test problems than the alternative formulations. The Duque et al. model performed poorly and could solve only the smallest test problems including 25 sites. This is consistent with their computational experience using CPLEX. The Jafari-Hearne model performed well only in the test problems including up to 100 sites and failed to solve most of the problems including 400 sites within the processing time limit. None of the problems including 900 or more sites could be solved to optimality by the Duque et al. and Jafari-Hearne models, whereas our model could solve all of the problems with 900 sites (each within two minutes) and most of the problems including 1600 sites. The second observation is the substantial reduction in solution times particularly when a large number of sites is considered. For the 400-site case (the largest problem that could be solved by the Jafari-Hearne model), our model was nearly thirty times faster and could solve all of the test problems under one minute whereas the Jafari-Hearne model took more than 15 minutes (on average). Model size is not the only factor that determines computational efficiency of MIP models. In many cases the model structure can be equally important. Although the Jafari-Hearne model is always smaller than our model (even after Presolve), our computational experience with randomly generated data sets shows that the Jafari-Harne model is computationally less efficient. This can be attributed to the structure of the p-median formulation. 

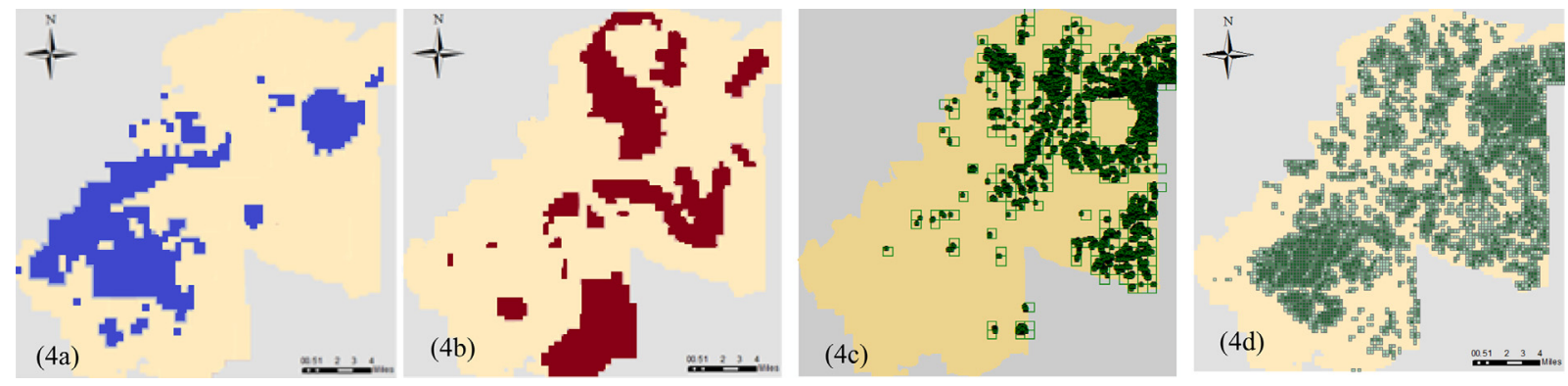

Fig. 4. Locations of the current (a) and planned (b) training areas, known GT burrows (c), and suitable habitat areas (d) (the darker the shade the higher the suitability).

In the test runs with our model, all possible pairs were considered when defining the $X_{k i}$ variables. The model sizes and solution times could be reduced substantially by eliminating distant pairs of sites during model generation without affecting the optimality of numerical solutions obtained after pruning (due to the compactness consideration, a site would not belong to a reserve centered at a faraway site). This is another important computational advantage of the pmedian formulation, which we have not exploited in the test runs. The graph-theoretic formulations are not suitable for such pruning.

\section{An empirical application}

We present an empirical application of the model described by (1)-(8), with and without incorporation of the habitat-adjusted distances given by (9), to select the best conservation management areas (CMA) for a keystone species, the Gopher Tortoise (GT), in Ft. Benning, Georgia. Over the past decades, the GT population in several southeastern states declined substantially (estimated as 80 percent) due to the loss of suitable habitats resulting from agricultural and urban development (BenDor, Westervelt, Aurambout, \& Meyer, 2009). Ft. Benning manages a significant amount of GT habitat areas within the boundaries of the installation. Currently, the installation is undergoing an expansion of its training mission, which requires using some of those lands more intensively for military training. The purpose of the analysis here is to determine the most suitable habitat areas that would support a targeted GT population without sacrificing the military training objectives. We address the problem as configuring a desired number $(n)$ of compact and connected CMAs, each providing a minimum habitat suitability index $(v h)$ while collectively providing the targeted total habitat suitability (th). Fig. 4 displays the nature of the problem. The current and planned intensive military training areas, shown in Fig. 4a and b, contain a large number of GT burrows, shown in Fig. 4c. The new CMAs will be selected from among the suitable areas, shown by the shaded cells in Fig. 4d, which are also outside the training areas.

The current and future military training areas were obtained as raster files from Ft. Benning. The habitat areas suitable for GT were obtained as raster files from the national biological information infrastructure (Elliott, Anderson, Bumback, Schmidt, \& Kramer, 2003). The two raster files were converted to ESRI shape files using ARC GIS 9.2. A $60 \times 60$ grid file, where each grid was $600 \mathrm{~m} \times 600 \mathrm{~m}$, was created using GEODA and the grid shape file was spatially joined with the above shape files using spatial join tool in ARC GIS. Based on the carrying capacity of each cell (derived from the habitat suitability index) and the existing number of observed GT burrows in that cell, the number of additional GT's that can be placed in each cell is calculated ( $h_{i}$ in constraints 5 and 6). Finally, the shortest paths and distances between pairs of sites are generated using Dijkstra's algorithm (Dijkstra, 1959).

The management of the GT populations within the installation can be conducted using a single large reserve or multiple smaller reserves. The reasons for considering multiple reserves are three-fold.
First, dividing the total GT population into smaller populations, each to be located in a different part of the installation, may safeguard each of them against potential diseases that may occur in other protected areas. Second, the habitat density in the southeast and northeast of the installation (see Fig. 4) suggests having at least two separate CMAs, one in each of those areas. Otherwise, either the single CMA would stretch over a large area and compactness would be compromised or some most suitable habitat areas would be left out. Third, configuring multiple CMAs allows more flexibility for the military when further expansion of training areas is needed in future. A single large CMA would limit the choices for placing a large chunk of military training area without sacrificing part of the large CMA. In the results presented below the model is solved for one and two reserves, namely $n=1$ and $n=2$, for a minimum habitat suitability index of 6000 for each CMA and the aggregate habitat suitability index ranging between 10,000 and 20,000. When a single CMA is configured the target habitat suitability index was varied in the range of 8000-12,000. For computational convenience we limited the maximum radius of each cluster to 10 cells by excluding the site pairs that are more than 10 cells apart when defining the $X_{k i}$ variables.

\section{Results and discussion}

We first found the optimum spatially unrestricted selection of GT habitat sites, namely the minimum number of sites that collectively provide 20,000 units of habitat suitability. ${ }^{14}$ This solution is displayed in Fig. 5a. As expected and stated at the outset, this selection includes a highly scattered subset of sites which have highest habitat suitability. Clearly this selection is not a meaningful CMA configuration since it would not allow movement of GTs from one protected site to another without traversing long distances between them through unsuitable or unprotected areas. Fig. $5 \mathrm{~b}$ and $\mathrm{c}$ shows the selection of one and two CMAs, respectively, with maximum overall compactness (but ignoring contiguity). Although these solutions include tightly clustered habitat patches and display a spatially improved configuration compared to the selection in Fig. 5a, they are still not satisfactory configurations because of the serious fragmentation (some of the habitat patches include single cells only).

Imposing constraint (8) establishes spatial connectivity, as shown in Fig. 6a-d. The largest single contiguous CMA (obtained with parameters $n=1, t h=12,000$ ) would be located in the southeast section of the installation where there are many moderately good sites (Fig. 6a). A functionally connected CMA with the same parameter specifications is also located in the same area (Fig. 6b). These reserves are substantially larger than both the spatially unconstrained case (specifically including 83 and 82 sites, as opposed to 39 sites; compare rows $\mathrm{C} 1$ and $\mathrm{D} 1$ against row $\mathrm{A} 1$ in Table 3 ) and the compact but not connected reserve configuration (comprised by 54 sites, row

\footnotetext{
14 This is done by using the covering problem: Minimize $\sum_{i} X_{i}$, such that : $\sum_{i} h_{i} X_{i} \geq$ th, $X_{i}=0,1$.
} 

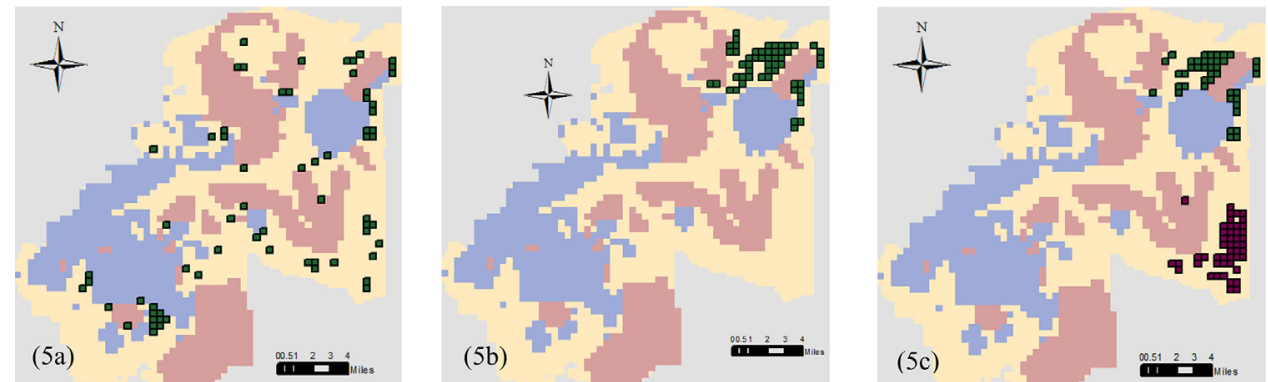

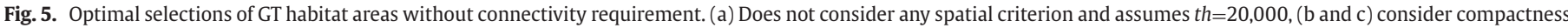

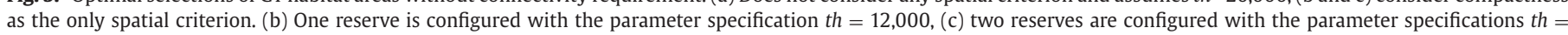
$20,000, v h=6000$ [See text for the meanings of $t h, v h$, and $n$ ].
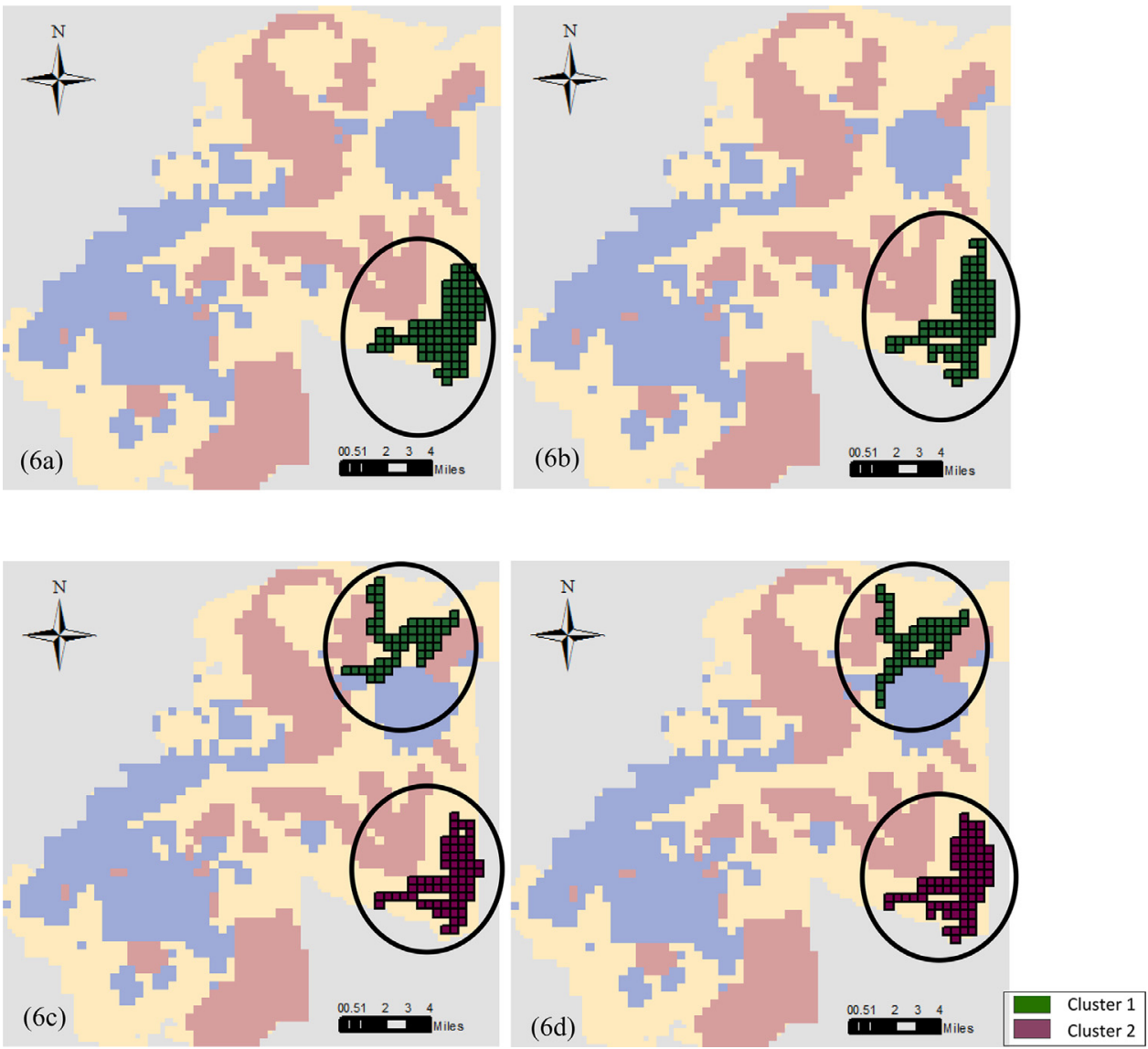

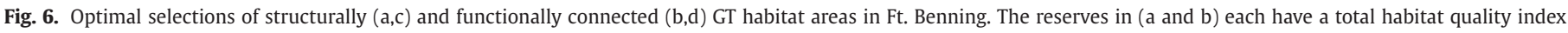

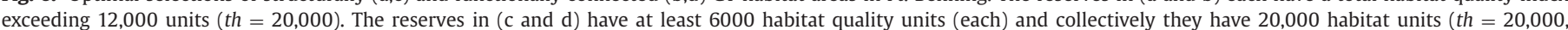
$v h=6000)$.

B1 in Table 3). These findings highlight the trade-off between ecological and economic considerations in conservation site selection. When two separate reserves are to be configured, each connected in itself and supporting a minimum viable GT population while together meeting the overall conservation target, the model selects one of the reserves again in the southeast section and the other in the northeast section of the installation. Fig. $6 \mathrm{c}$ and $\mathrm{d}$ displays those reserves obtained with the parameter specifications $n=2$, th $=20,000$, and $v h=6000$. Although these reserves have similar habitat characteristics, the total number of selected sites is increased when functional connectivity is imposed, specifically from 119 to 126 sites. This is due to the replacement of some poor quality sites, which connect high quality sites in the contiguous configuration, with a few additional higher quality sites to establish better connections (functionally improved routes).
Both structural and functional contiguity requirements led to larger CMAs, which increased the total distances from the reserve centers (thus, decreased compactness). Instead of the total distance (plain or habitat-adjusted) a more representative measure of compactness can be the average distance obtained by dividing the total distance from the reserve center(s) by the number of sites included in the reserve(s). Fig. 7 displays the relationships between the ordinary and functional average distances versus the size of the optimal reserves for the case of $n=2, v h=6000$ and $t h=10,000-20,000$. It is evident from the graphs that an expansion in the total habitat quality increases the average distance proportionally, both for ordinary distances and functional distances, thus reducing the overall compactness of the reserve. This is because of having to select more marginal areas farther from the centers to achieve the targeted habitat quality, thus having to travel a larger distance to benefit from the habitat 
7a. Structural Connectivity Imposed

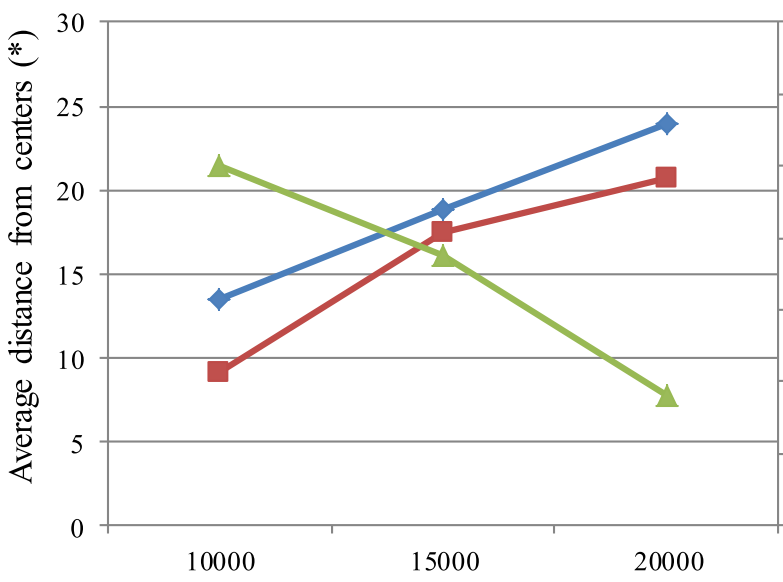

Size of conservation area (in habitat units)
220

210

200

190

180

170

160

150

7b. Functional Connnectivity Imposed

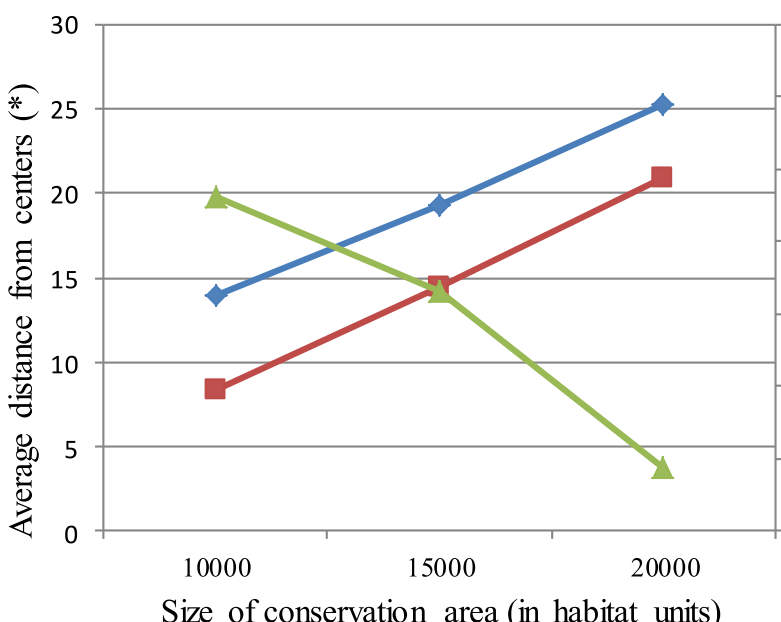

220

210

200

190

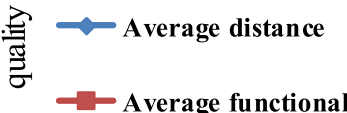

distance

180

ב्ב - Average habitat

170

흉

160

150

Size of conservation area (in habitat units)

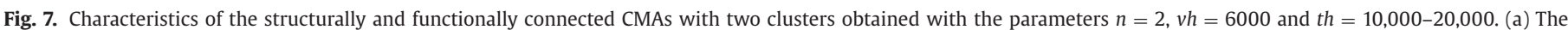

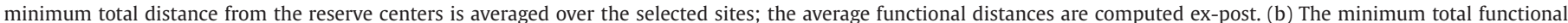

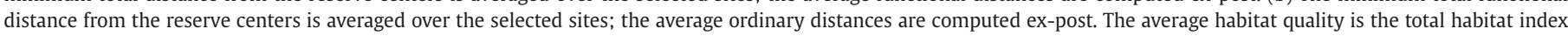
divided by the number of selected sites.

Table 3

Selected statistics for the Ft. Benning model with alternative model specifications and 12,000 total habitat units.

\begin{tabular}{|c|c|c|c|c|c|c|c|c|}
\hline \multirow[t]{2}{*}{ Model type } & \multirow[t]{2}{*}{ No. reserves } & \multirow[t]{2}{*}{ No. sites } & \multirow{2}{*}{$\begin{array}{l}\text { Total } \\
\text { habitat }\end{array}$} & \multirow{2}{*}{$\begin{array}{l}\text { Euclidean } \\
\text { distance }\end{array}$} & \multirow{2}{*}{$\begin{array}{l}\text { Functional } \\
\text { distance }\end{array}$} & \multicolumn{2}{|c|}{ Model size } & \multirow{2}{*}{$\begin{array}{l}\text { Processing } \\
\text { time (s) }\end{array}$} \\
\hline & & & & & & Equations & Variables & \\
\hline A1) Set covering & $\mathrm{n} / \mathrm{a}$ & 39 & 12,284 & $\mathrm{n} / \mathrm{a}$ & $\mathrm{n} / \mathrm{a}^{\mathrm{a}}$ & 2 & 913 & 0.02 \\
\hline B1) Clustering only ${ }^{\mathrm{b}}$ & 1 & 54 & 12,022 & 261.3 & $\mathrm{n} / \mathrm{a}^{\mathrm{a}}$ & 94,725 & 93,809 & 101.0 \\
\hline $\begin{array}{l}\text { C1) Compact } \& \text { connected - } \\
\text { Euclidean distances }^{\mathrm{b}}\end{array}$ & 1 & 83 & 12,022 & 366.5 & 1755.5 & 187,621 & 93,809 & 49.7 \\
\hline $\begin{array}{l}\text { D1) Compact (Euclidean) and } \\
\text { connected (functional) }\end{array}$ & 1 & 82 & 12,002 & 371.5 & 1670.7 & 185,043 & 93,809 & 34.9 \\
\hline $\begin{array}{l}\text { E1) Compact and connected - } \\
\text { functional distances }{ }^{c}\end{array}$ & 1 & 82 & 12,002 & 371.5 & 1670.7 & 185,043 & 93,809 & 36.0 \\
\hline B2) Clustering only ${ }^{b}$ & 2 & 53 & 12,001 & 149.8 & $\mathrm{n} / \mathrm{a}^{\mathrm{a}}$ & 94,725 & 93,809 & 53.3 \\
\hline $\begin{array}{l}\text { C2) Compact \& connected - } \\
\text { Euclidean distances }^{\mathrm{b}}\end{array}$ & 2 & 63 & 12,037 & 167.6 & 671.6 & 187,621 & 93,809 & 67.5 \\
\hline $\begin{array}{l}\text { D2) Compact (Euclidean) and } \\
\text { connected (functional) }\end{array}$ & 2 & 63 & 12,000 & 166.4 & 680.2 & 185,043 & 93,809 & 29.4 \\
\hline $\begin{array}{l}\text { E2) Compact and connected - } \\
\text { dunctional distances }{ }^{c}\end{array}$ & 2 & 63 & 12,013 & 186.8 & 612.8 & 185,043 & 93,809 & 42.7 \\
\hline
\end{tabular}

a There were discontinuities.

b Functional compactness (measured in functional distances) is calculated ex-post.

${ }^{c}$ Euclidean compactness (measured in functional distances) is calculated ex-post. 
services provided by those areas. Another important observation is the declining average habitat quality as a larger reserve is configured, which is again expected for the same reasons. A perplexing result is the slightly higher average habitat quality when structural contiguity is imposed (Fig. 7a) compared to the case when functional contiguity is imposed (Fig. 7b). This happens because poor short cuts are eliminated when functional distances are considered, therefore more sites are needed to connect good habitat patches, which in turn reduces the average habitat quality. Although the average habitat quality is worsened, the average movement resistance is improved (indicated by the lower average functional distances in Fig. 7b than in 7a). This is consistent with the objective stated at the outset, namely enhancement of functional connectivity of the reserved areas by identifying better routes.

Table 3 displays some summary statistics associated with two sets of model solutions that assume alternative compactness and connectivity criteria. Rows C1-E1 are associated with one large reserve while rows C2-E2 assume two smaller reserves, both obtained with th $=12,000$. Compactness and connectivity are formulated in three different ways in each block (see the notes in Table 3). The first important finding is the reduced size of the reserve, namely 63 selected sites versus 82 and 83 , when two reserves are configured instead of one large reserve. This is an expected result because of the selection of fewer habitat-rich core areas in C2-E2, whereas many more poorquality sites have to be selected in C1-E1 in order to build a connected reserve. The second important observation is the trade-off between compactness and connectivity when functional distances are used instead of ordinary distances in the objective function and the connectivity constraints. Specifically, when compactness is measured using physical distances, functional connectivity is compromised because of the selection of poor quality sites that provide short-cuts and reduce the total distances from the reserve centers. This increases the total functional distance, however (poorer functional connectivity). In contrast, maximizing functional connectivity (minimizing the total functional distance) reduces the geometric compactness (increases the total physical distance from the reserve centers).

\section{Concluding remarks}

This article presented a linear integer programming formulation to incorporate reserve compactness and landscape connectivity as spatial criteria in reserve site selection. Compactness is achieved by minimizing the sum of pairwise distances between all sites assigned to a reserve and a central site of that reserve, both determined by the model simultaneously. The model includes an explicit constraint to achieve spatial contiguity, namely if a site is to be selected an adjacent site closer to the central site must also be selected. Landscape connectivity is defined in two different ways: structural contiguity and functional connectivity. In the first case, we use ordinary distances between selected sites and the central sites they are associated with, while in the second case we use habitat adjusted distances to reflect the difficulty of species' movement within the protected areas. We presented a case study involving the protection of a keystone species at risk. The results show that the optimal reserves become less compact and include more sites with lower quality as the targeted habitat quality is increased.

The model and the empirical example presented here focus on one species only. With appropriate modifications, the model can be extended to the case of multiple species. This requires additional index sets, more variables and more constraints (as in Dissanayake, Önal, \& Westervelt, 2011). For the sake of space and readability, we did not present the details of the multi-species extension here.

The present analysis focuses on spatial properties of the reserved areas only, ignoring the properties of the remaining landscape. In some cases, islands or thin deep bays of non-reserve areas may be placed within the reserved areas (Fig. 6d). Such areas may not be suitable for alternative uses, thus they have to be managed as part of the reserve. In the particular case study presented here this was not an issue because the land is already owned by the military, but in general this means additional cost that must be accounted for. Finally, spatial layout of the non-reserve areas can often be equally important as that of the reserved areas (e.g., they may have to be contiguous). Incorporating spatial considerations for both reserved and non-reserved areas can be done by using a multiple land use model, as in Dissanayake et al. (2011) or by including additional variables and constraints in the model to achieve the desired properties. We note, however, that this may adversely affect the size and computational efficiency of the model.

\section{Acknowledgments}

This research was partially supported by the ERDC-CERL Project no. W81EWF-7204-6330, CREES Project no. ILLU 05-0361, and National Natural Science Foundation of China (71202096).

\section{References}

Adriaensen, F., Chardon, J. P., De Blust, G., Swinnen, E., Villalba, S., Gulinck, H., \& Matthysen, E. (2003). The application of 'least-cost' modelling as a functional landscape model. Landscape and Urban Planning, 64, 233-247.

BenDor, T., Westervelt, J. D., Aurambout, J. P., \& Meyer, W. (2009). Simulating population variation and movement within fragmented landscapes: An application to the gopher tortoise (Gopherus polyphemus). Ecological Modelling, 220, 867-878.

Bélisle, M. (2005). Measuring landscape connectivity: The challenge of behavioral landscape ecology. Ecology, 86, 1988-1995.

Benton, N., Ripley, J. D., \& Powledge, F. (2008). Conserving biodiversity on military lands: A guide for natural resources managers. Arlington, Virginia: NatureServe http://www.dodbiodiversity.org.

Briers, R. A. (2002). Incorporating connectivity into reserve selection procedures. Biological Conservation, 103, 77-83.

Bunn, A. G., Urban, D. L., \& Keitt, T. H. (2000). Landscape connectivity: A graph theoretic perspective. Journal of Environmental Management, 59, 265-278.

Camm, J. D., Polasky, S., Solow, A., \& Csuti, B. (1996). A note on optimal algorithms for reserve site selection. Biological Conservation, 78, 353-355.

Carvajal, R., Constantino, M., Goycoolea, M., Vielma, J. P., \& Weintraub, A. (2013). Imposing connectivity constraints in forest planning models. Operations Research, 61, 824-836.

Cerdeira, J. O., \& Pinto, L. S. (2005). Requiring connectivity in the set covering problem. Journal of Combinatorial Optimization, 9, 35-47.

Cerdeira, J. O., Gaston, K. J., \& Pinto, L. S. (2005). Connectivity in priority area selection for conservation. Environmental Modeling and Assessment, 10, 183-192.

Cerdeira, J. O., Pinto, L. S., Cabeza, M., \& Gaston, K. J. (2010). Species specific connectivity in reserve-network design using graphs. Biological Conservation, 143, 408-415.

Christofides, N. (1975). Graph theory: An algorithm approach. New York: Academic Press.

Church, R. L., \& ReVelle, C. S. (1974). The maximum covering location problem. Papers in Regional Science Association, 32, 101-118.

Church, R. L., Stoms, D. M., \& Davis, F. W. (1996). Reserve selection as a maximal covering location problem. Biological Conservation, 76, 105-112.

Cocks, K. D., \& Baird, I. A. (1989). Using mathematical programming to address the multiple reserve selection problem: An example from the Eyre Peninsula, South Australia. Biological Conservation, 49, 113-130.

Conrad, J. M., Gomes, C. P., van Hoeve, W., Sabharwal, A., \& Suter, J. F. (2012). Wildlife corridors as a connected subgraph problem. Journal of Environmental Economics and Management, 63, 1-18.

Cova, T. J., \& Church, R. L. (2000). Contiguity constraints for single-region site search problems. Geographical Analysis, 32, 306-329.

Dijkstra, E. W. (1959). A note on two problems in connexion with graphs. Numerische Mathematik, 1, 269-271. doi:10.1007/BF01386390.

Diersing, V. E., Shaw, R. B., \& Tazik, D. J. (1992). US Army Land Condition-Trend Analysis (LCTA) Program. Environmental Management, 16, 405-414.

Dissanayake, S., Önal, H., Westervelt, J. D., \& Balbach, H. E. (2012). Incorporating species relocation in reserve design models: An example from Ft. Benning GA. Ecological Modelling, 224, 65-75.

Dissanayake, S. T. M., Önal, H., \& Westervelt, J. D. (2011). Optimum selection of conservation reserves: Extensions to multiple land use. Military Operations Research, 16, $65-76$.

DoD (2011). Instruction Number 4715.03, subject: Natural resources conservation program. Available online at: http://www.dtic.mil/whs/directives/corres/pdf/ 471503p.pdf

Duque, J. C., Church, R. L., \& Middleton, R. S. (2011). The p-regions problem. Geographical Analysis, 43, 104-126.

Elliott, M., Anderson, L., Bumback, B., Schmidt, J.P., \& Kramer, L. (2003). Georgia GAP reptile models. Gap Analysis Project. http://gapanalysis.nbii.gov/.

Etherington, T. R., \& Holland, E. P. (2013). Least-cost path length versus accumulatedcost as connectivity measures. Landscape Ecology, 28, 1223-1229. 
Fischer, D. T., \& Church, R. L. (2003). Clustering and compactness in reserve site selection: An extension of the biodiversity management area selection model. Forest Science, 49, 555-565.

Flather, C. H., Joyce, L. A., \& Bloomgarden, C. A. (1994). Species endangerment patterns in the United States. General technical report RM-241. Fort Collins, Colorado, USA: USDA Forest Service.

Flather, C. H., Knowles, M. S., \& Kendall, I. A. (1998). Threatened and endangered species geography. Bioscience, 48, 365-376.

Haight, R,G., \& Snyder, S. A. (2009). Integer programming methods for reserve selection and design. In A. Moilanen, K. A. Wilson, \& H. P. Possingham (Eds.), Spatial conservation prioritization: Quantitative methods and computational tools. Oxford University Press.

Hanski, I. (1999). Metapopulation ecology. Oxford: Oxford University press.

Jafari, N., \& Hearne, J. (2013). A new method to solve the fully connected reserve network design problem. European Journal of Operational Research, 231, 202209.

Kadoya, T. (2009). Assessing functional connectivity using empirical data. Population Ecology, 51, 5-15.

Kirkpatrick, J. B. (1983). An iterative method for establishing priorities for the selection of nature reserves: An example from Tasmania. Biological Conservation, 25, 127134

Marianov, V., ReVelle, C. S., \& Snyder, S. A. (2008). Selecting compact habitat reserves for species with differential habitat size needs. Computers and Operations Research, $35,475-487$.

Miller, J. R., Snyder, S. A., Skibbe, A. M., \& Haight, R. G. (2009). Prioritizing conservation targets in a rapidly urbanizing landscape. Landscape and Urban Planning, 93, 123131.

Miller, C. E., Tucker, A. W., \& Zemlin, R. A. (1960). Integer programing formulations of traveling salesman problems. Journal of the Association of Computer Machinery, 7, 326-329.

Moilanen, A., \& Hanski, I. (1998). Metapopulation dynamics: Effects of habitat quality and landscape structure. Ecology, 79, 2503-2515.

Moilanen, A., \& Hanski, I. (2001). On the use of connectivity measures in spatial ecology. Oikos, 95, 147-151.

Moilanen, A., Wilson, K. A., \& Possingham, H. P. (2009). Spatial conservation prioritization: quantitative methods and computational tools. Oxford University Press.

Nalle, D. J., Arthur, J. L., Montgomery, C. A., \& Sessions, J. (2002). Economic and spatial impacts of an existing reserve network on future augmentation. Environmental Modeling and Assessment, 7, 99-105.

Önal, H., \& Briers, R. A. (2002). Incorporating spatial criteria in optimum reserve network selection. Proceedings of the Royal Society of London: Biological Sciences, 269, 2437-2441.

Önal, H., \& Briers, R. A. (2003). Selection of a minimum-boundary reserve network using integer programming. Proceedings of the Royal Society of London: Biological Sciences, 270, 1487-1491.

Önal, H., \& Briers, R. A. (2005). Designing a conservation reserve network with minimal fragmentation: A linear integer programming approach. Environmental Modeling and Assessment, 10, 193-202.

Önal, H., \& Briers, R. A. (2006). Optimum selection of a connected conservation reserve network. Operations Research, 5, 379-388.

Önal, H., \& Wang, Y. (2008). A Graph theory approach for designing conservation reserve networks with minimal fragmentation. Networks, 52, 142-152.

Önal, H., \& Yanprechaset, P. (2007). Site accessibility and prioritization of nature reserves. Ecological Economics, 60, 763-773.

Pinto, N., \& Keitt, T. (2009). Beyond the least-cost path: Evaluating corridor redundancy using a graph theoretic approach. Landscape Ecology, 24, 253-266.

Polasky, S., Camm, J. D., \& Garber-Yonts, B. (2001). Selecting biological reserves costeffectively: An application to terrestrial vertebrate conservation in Oregon. Land Economics, 77, 68-78.

Possingham, H. P., Ball, I., \& Andelman, S. (2000). Mathematical methods for identifying representative reserve networks. In S. Ferson, \& M. Burgman (Eds.), Quantitative methods for conservation biology (pp. 291-306). New York: Springer.

Pressey, R. L., Humphries, C. J., Margules, C. R., Vane-Wright, R. I., \& Williams, P. H. (1993). Beyond opportunism: Key principles for systematic reserve selection. Trends in Ecology and Evolution, 8, 124-128.

Pressey, R. L., Possingham, H. P., \& Day, J. R. (1997). Effectiveness of alternative heuristic algorithms for identifying indicative minimum requirements for conservation reserves. Biological Conservation, 80, 207-219.
Rothley, K. D. (1999). Designing bioreserve networks to satisfy multiple, conflicting demands. Ecological Applications, 9, 741-750.

Ruliffson, A. A. Haight, R. G. Gobster, P. H. \& Homans, F. R (2003). Metropolitan natura area protection to maximize public access and species representation. Environmental Science and Policy, 6, 291-299.

Shirabe, T. (2005). A model of contiguity for spatial unit allocation. Geographical Analysis, 37, 2-16.

Snyder, S. A., Miller, J. R., Skibbe, A. M., \& Haight, R. G. (2007). Habitat Acquisition Strategies for Grassland Birds in an Urbanizing Landscape. Environmental Management 40, 981-992.

Stein, B. A., Scott, C., \& Benton, N. (2008). Federal lands and endangered species: The role of military and other federal lands in sustaining biodiversity. Bioscience, 58 , 339-347.

Taylor, P. D., Fahrig, L., Henein, K., \& Merriam, G. (1993). Connectivity is a vital element of landscape structure. Oikos, 68, 571-573.

Taylor, P. D., Fahrig, L., \& With, K. A. (2006). Landscape connectivity: A return to the basics. In K. R. Crooks, \& M. Sanjayan (Eds.), Connectivity conservation (pp. 29-43). Cambridge University Press.

Tischendorf, L., \& Fahrig, L. (2000). On the usage and measurement of landscape connectivity. Oikos, 90, 7-19.

Tóth, S. F., \& McDill, M. (2008). Promoting large, compact forest patches in harvest scheduling models. Environmental Modeling and Assessment, 13, 1-15.

Toregas, C., \& ReVelle, C. S. (1973). Binary logic solutions to a class of location problems. Geographical Analysis, 5, 145-155.

Tóth, S. F., Haight, R. G., Snyder, S. A., Sonney, G., Miller, J. R., Gregory, M. S., \& Skibbe, A. M. (2009). Reserve selection with minimum contiguous area restrictions: An application to open space protection planning in suburban Chicago. Biological Conservation, 142, 1617-1627.

Underhill, L. G. (1994). Optimal and suboptimal reserve selection algorithms. Biological Conservation, 70, 85-87.

Urban, D. L. \& Keitt, T. H. (2001). Landscape connectivity: A graph theoretic perspective. Ecology, 82, 1205-1218.

Van Teeffelen, A. J. A., Cabeza, M., \& Moilanen, A. (2006). Connectivity, probabilities and persistence: comparing reserve selection strategies. Biodiversity and Conservation, $15,899-919$.

Wang, Y., \& Önal, H. (2011). Designing connected nature reserve networks using a graph theory approach. Acta Ecologica Sinica, 31, 235-240.

Wang, Y., \& Önal, H. (2013). Designing a connected nature reserve using a network flow theory approach. Acta Ecologica Sinica, 33, 253-259.

Williams, J. C. (1998). Delineating protected wildlife corridors with multiple-objective programming. Environmental Modeling and Assessment, 3, 77-86.

Williams, J. C. (2001). A linear-zero-one programming model for the minimum spanning tree problem in planar graphs. Networks, 39, 53-60.

Williams, J. C. (2008). Optimal reserve site selection with distance requirements. Computers and Operations Research, 35, 488-498.

Williams, J. C., \& Snyder, S. A. (2005). Restoring habitat corridors in fragmented landscapes using optimization and percolation models. Environmental Modeling and Assessment, 10, 239-250.

Williams, J. C., \& ReVelle, C. S. (1996). A 0-1 programming approach to delineating protected reserves. Environment and Planning B, 23, 607-622.

Williams, J. C., \& ReVelle, C. S. (1997). Applying mathematical programming to reserve selection. Environmental Modeling and Assessment, 2, 167-175.

Williams, J. C., \& ReVelle, C. S. (1998). Reserve assemblage of critical areas: A zero-one programming approach. European Journal of Operational Research, 104, 497-509.

Williams, J. C., ReVelle, C. S., \& Levin, S. A. (2005). Spatial attributes and reserve design models: A review. Environmental Modeling and Assessment, 10, 163-181.

Wright, J. C., ReVelle, C. S., \& Cohon, J. (1983). The multiobjective integer programming model for the land acquisition problem. Regional Science and Urban Economics, 13 , 31-53.

Young, H. P. (1988). Measuring the compactness of legislative districts. Legislative Studies Quarterly, 13, 105-115.

Zoltners, A. A., \& Sinha, P. (1983). Sales territory alignment - a review and model. Management Science, 29, 1237-1256.

Zeller, K. A., McGarigal, K., \& Whiteley, A. R. (2012). Estimating landscape resistance to movement: A review. Landscape Ecology, 27, 777-797.

Zhou, S. R., \& Wang, G. (2006). One large, several medium, or many small? Ecological Modelling, 191, 513-520. 